\title{
도코
}

Revista GEON (Gestión, Organizaciones y Negocios.) ISSN: 2346-3910 en línea

revistageon@unillanos.edu.co

Universidad de los Llanos

Colombia

Torres-Flórez, Dagobertoi.

La importancia de la gestión del desempeño en

las organizaciones

Revista GEON, Vol. 5, No. 1, 2018

Pág. 4-5

Disponible en: https://doi.org/10.22579/23463910.2

\footnotetext{
${ }^{\mathrm{i}}$ http://orcid.org/0000-0002-7925-3005
}

Esta publicación se encuentra bajo licencia: Creative Commons

Reconocimiento-

NoComercial-

SinObraDerivada

4.0 Internacional

\section{@) $\mathbb{P Q \Theta}$}

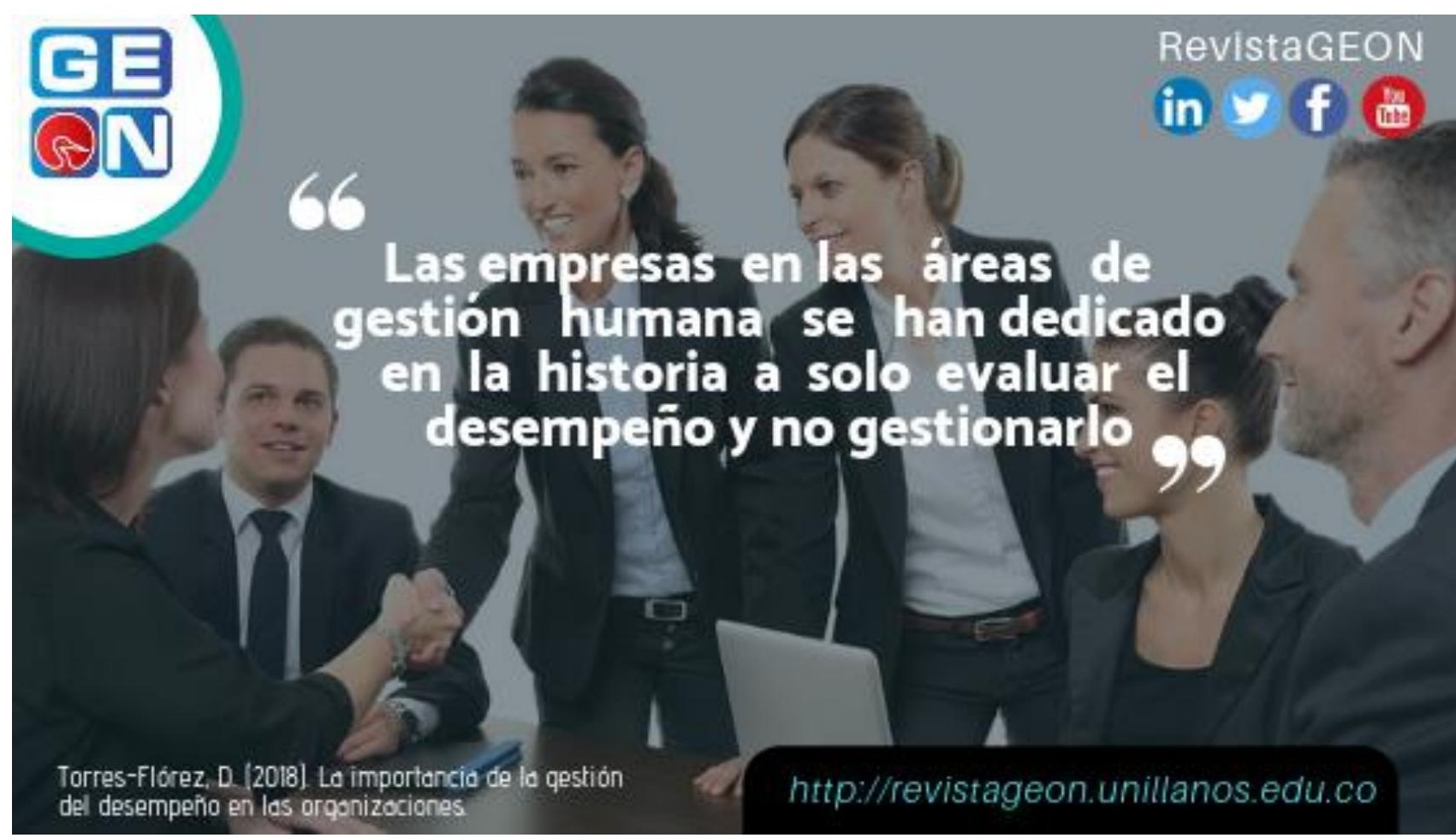




\section{REVISTA GEON}
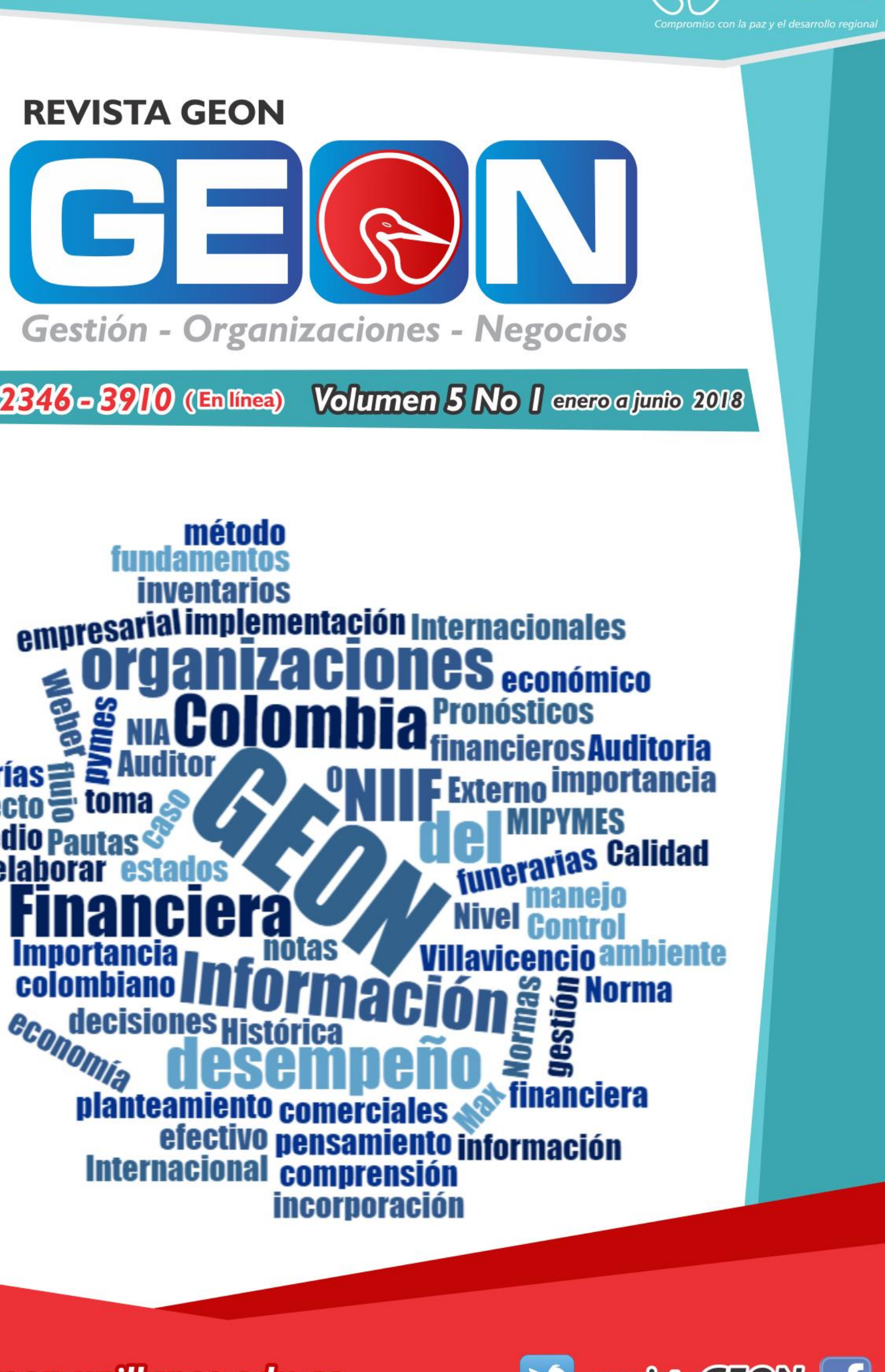

Gestión - Organizaciones - Negocios

ISSN 2346-3910 (Enlinea) Volumen 5No I enero a junio 2018

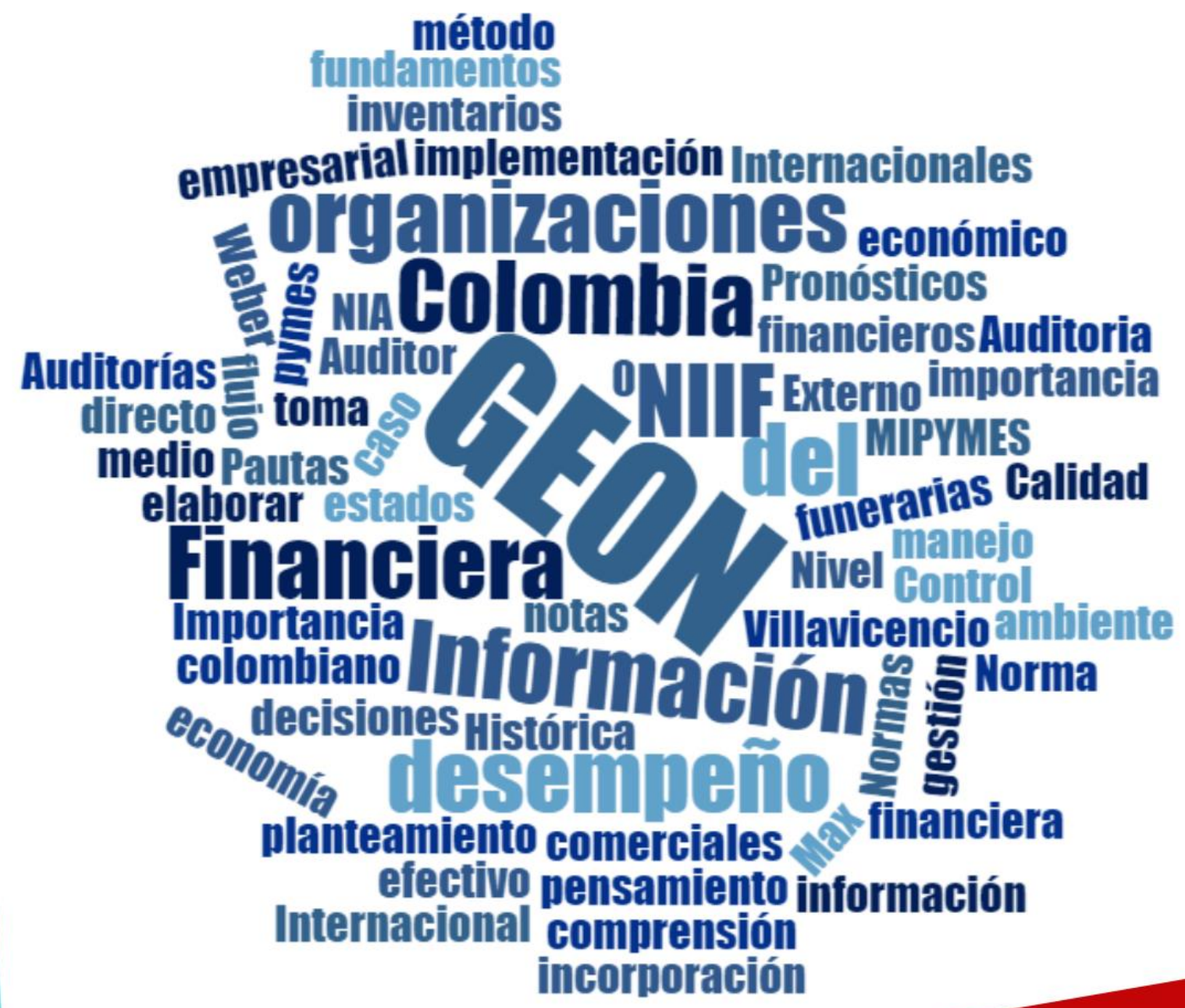

http://revistageon.unillanos.edu.co

revistaGEON f 


\section{EDITORIAL}

\section{La importancia de la gestión del desempeño en las organizaciones.}

Dagoberto Torres-Flórez

Phd (c) Ciencias Económicas y administrativas, dtorres@unillanos.edu.co, Colombia

\section{Director - Editor Revista GEON \\ @dagoto@RevistaGEON}

Las organizaciones se han preocupado por desarrollar estrategias para la motivación de los colaboradores siempre buscando la productividad de ellos expresados en un crecimiento organizacional a través de una dignificación humana del colaborador en su ambiente empresarial. Sin embargo, en las áreas de gestión humana se han dedicado en la historia a solo evaluar el desempeño y no gestionarlo. Para ello es importante diseñar una práctica que busque gestionar el desempeño adecuadamente, que logre encontrar beneficios tanto para la empresa como para el colaborador, basado en una planeación, acompañamiento, medición, retroalimentación y plan de mejora o sostenibilidad.

Todo proceso enfocado a la gestión debe iniciar con un planear, en el la importancia de definir el qué se evaluará, para ello es necesario tener en cuenta aspectos claves de nivel estratégico y aquellas competencias que influyen en la productividad tanto individual como colectivo, luego de ello es importante establecer todos aquellos elementos que permitan visualizar como se desarrollará el proceso de gestión del desempeño, aspectos como dónde se hará, cada cuanto, quién lo realizará, responsables o actores en el proceso, definir el para qué y con este elemento permita entregarle valor al proceso y sea percibido por los colaboradores, a esto se sugiere desarrollar la mayoría de las palabras preguntas que permitan poder dejar todo establecido y así minimizar el riesgo de error en el proceso, pero no olvidar la importancia de definir el cómo, reflejado en la metodología a utilizar y el cuanto que es el valor económico que puede costar el proceso y así apropiarlo al presupuesto de la institución.

Seguido de planear, es significativo el acompañar al colaborador, es el paso con mayor valor pensado en el desempeño esperado, ya que con los elementos definidos todos los actores deben trabajar entre sí para poder trabajar en equipo y así lograr tanto los objetivos individuales como los organizacionales, con la importancia de la labor del supervisor en tener un rol de guía y de apoyo a estos colaboradores para el desarrollo de sus actividades.

$\mathrm{Al}$ ser un proceso relacionado con la labor es importante medir el desempeño y con ello permitirá conocer el estado tanto de las persona, como del área y de la 
organización respecto a su desempeño para que así se puedan tomar decisiones siempre enfocadas a la mejora de todos los actores de la organización, es aquí donde los encargados deben implementar lo establecido en la planeación, lo que ayudará a ser eficiente en el aprovechamiento del tiempo y el desarrollo del proceso, aquí es importante ya conocer quienes actuaran en la medición (definidos en la planeación), ya que cada persona involucrada en la medición debe conocer la importancia, la objetividad y el fin propio del proceso. En este paso se deben generar unos resultados sean cuantitativos $\mathrm{O}$ cualitativos de acuerdo con la metodología definida en la planeación.

Al conocer los resultados de desempeño individual, por área y organizacional es importante retroalimentar la medición realizada, destacando fortalezas y debilidades que permitan crear un ambiente de mejora continua, este paso debe estar planeado, con los canales de comunicación que se utilizarán, que lleven a que cada persona que hace parte de la empresa se sensibilice de lo que debe mejorar y aquellos que se destaquen en la medición tengan su reconocimiento respectivo y ahí se conecten con las políticas de aumentos e incentivos que con las que se cuente.

Luego de retroalimentar sigue establecer el plan de mejora y sostenibilidad, el cual es un documento formal e informal (según lo planeado) que permitirá que el colaborador proponga como mejorar sus debilidades y sostener sus fortalezas en la búsqueda del crecimiento individual y organizacional, al definirse el plan es importante que el supervisor o persona responsable del desempeño establezca las acciones necesarias de seguimiento, para ello se sugiere volver a iniciar con el ciclo para la gestión del desempeño organizacional.

En este caso la planeación se limitará a revisar si lo desarrollado en el anterior proceso de gestión del desempeño fue optimo en que se falló y en que se puede mejorar, ya en el acompañamiento se busca guiar el desempeño teniendo en cuenta el plan de mejoramiento y sostenibilidad y todo aquello que permita obtener un desempeño ideal siempre promocionando la mejora continua, sin embargo, si el supervisor al realizar este paso encuentra que el colaborador no tiene una actitud de mejora respecto a su plan es importante que se hagan las respectivas acciones sobre el interés colectivo del particular. Luego medir al retroalimentar aquí es importante comparar los resultados del periodo anterior y poder tomar decisiones necesarias siempre entregando prioridad a lo colectivo sobre lo individual, paso seguido al hacer el nuevo plan de mejora conversar sobre las experiencias del diseño y ejecución del plan planteado anteriormente.

Esta es una propuesta para utilizar que sugiere tener un estado ideal de desempeño, a ello es valioso comprender que se busca es gestionar el desempeño y un ambiente de mejora continua, no solo quedarse en evaluar. 